\title{
ANÁLISE AEROMAGNETOMÉTRICA E RADIOMÉTRICA DA REGIÃO DE CAMARGOS, BORDA LESTE DO QUADRILÁTERO FERRÍFERO, MG, BRASIL
}

\author{
AEROMAGNETOMETRIC AND RADIOMETRIC ANALYSIS OF THE CAMARGOS`REGION, \\ EAST BORDER OF THE IRON QUADRANGLE, MG, BRAZIL
}

Luiz Henrique CARDOSO; Luis de Almeida Prado BACELLAR

Universidade Federal de Ouro Preto, Núcleo de Geotecnia da Escola de Minas. Campus Universitário Morro do Cruzeiro, s/n, Bauxita - Ouro Preto - MG. E-mails: lhcardosoop@hotmail.com; luisapbacellar@gmail.com

\author{
Introdução \\ Contextualização Geológica \\ Materiais e Métodos \\ Resultados do Processamento de Dados \\ Discussões dos Resultados \\ Conclusões \\ Agradecimentos \\ Referências
}

\begin{abstract}
RESUMO - Este trabalho investiga os aspectos geológicos e geoeconômicos da região de Camargos, situada na borda leste do Quadrilátero Ferrífero, através de análise geofísica. Sobre a região da qual tem sido explotado minério de ouro desde o Século XVII, há poucos relatos de literatura geológica. Assim, visando contribuir ao entendimento geológico de Camargos, são apresentados o produto de processamento e a interpretação de banco de dados geofísicos aerolevantados de magnetometria e radiometria. No tocante à contextualização geológica, o embasamento que é constituído por gnaisses está exposto pelo Horst de Camargos. As serras são sustentadas pelos quartzitos do Grupo Maquiné entre os quais afloram escamas tectônicas dos xistos do Grupo Nova Lima. Sequências do Supergrupo Minas afloram na porção oeste e constituem a Homoclinal de Camargos, na qual é observada a inversão das sequências litológicas, visto a influência do domínio dos sistemas de falhas de empurrão da Água Quente e de Fundão-Cambotas. Depósitos aluvionares são observados em planície de inundação confinada. A interpretação geofísica mais importante foi a percepção de zonas de cisalhamento e atividade de hidrotermalismo, o que contribui em parte, ao entendimento das mineralizações de ouro que estão relacionadas às sequências do Supergrupo Rio das Velhas na região.
\end{abstract}

Palavras-chave: Camargos. Quadrilátero Ferrífero. Magnetometria. Radiometria. Ouro.

ABSTRACT - This survey investigates the geological and geoeconomic aspects of the Camargos region, located on the eastern border of the Iron Quadrangle, through geophysical analysis. About the region from which gold ore has been exploited since the $17^{\text {th }}$ Century, there are few accounts of geological literature. Thus, in order to contribute to the geological understanding of Camargos, the processing result and interpretation of the aereal geophysical datas bank of magnetometry and radiometry is presented. In short, the geological contextualization includes the basement constituted by gneisses that are exposed by Camargos' Horst. The saws are supported by the quartzites of the Maquiné Group, among which are the tectonic slices of schists of the Nova Lima Group. Sequences of the Supergroup Minas arise in the western portion and constitute the Camargos' Homoclinal, in which the inversion of the lithological sequences is observed, due to the influence of the domain of the Água Quente’s and Fundão-Cambotas' thrust fault systems. Alluvial deposits are observed in a confined floodplain. The most important geophysical interpretation was the perception of shear zones and hydrothermal activity. It contributes in part to the understanding of the gold mineralizations that are related to the Rio das Velhas Supergroup sequences in the region.

Keywords: Camargos. Iron Quadrangle. Magnetometry. Radiometry. Gold.

\section{INTRODUÇÃO}

Após o catastrófico evento de rompimento de barragem de rejeitos de mineração em 2015 no município de Mariana - MG, uma das regiões afetadas, Camargos, objeto de estudo deste trabalho, antes pouco conhecida, ganhou espaço tocante ao seu valor histórico-cultural para o Brasil. Por trás disto, há uma história de muita riqueza que fora explotada da região e que perdura há séculos.

A figura 1 apresenta a localização da área em estudo: entre as coordenadas 664198m E, 7756285m S e 669677m E, 7759875m S, Datum
Córrego Alegre, Zona 23S. O acesso a partir da capital Belo Horizonte é feito pela BR-356 até Ouro Preto, onde se segue pela MG-129 até a altura da Mina Del Rei. A partir daí, há uma estrada de terra (Estrada Real) de 20 km até Camargos.

A região foi explorada por bandeirantes enviados pela Coroa Portuguesa no período colonial, dentre eles, a família Camargo (Silva, 2012), à procura de ouro. Daí, com a exploração aurífera nos séculos XVII e XVIII, foi desenvolvido um pequeno vilarejo, Camargos, 
no qual até a atualidade, é observado atividade

balizam uma ideia sobre a quantidade de minério garimpeira. Relatos de moradores mais antigos

que ainda fora explotado no século passado.

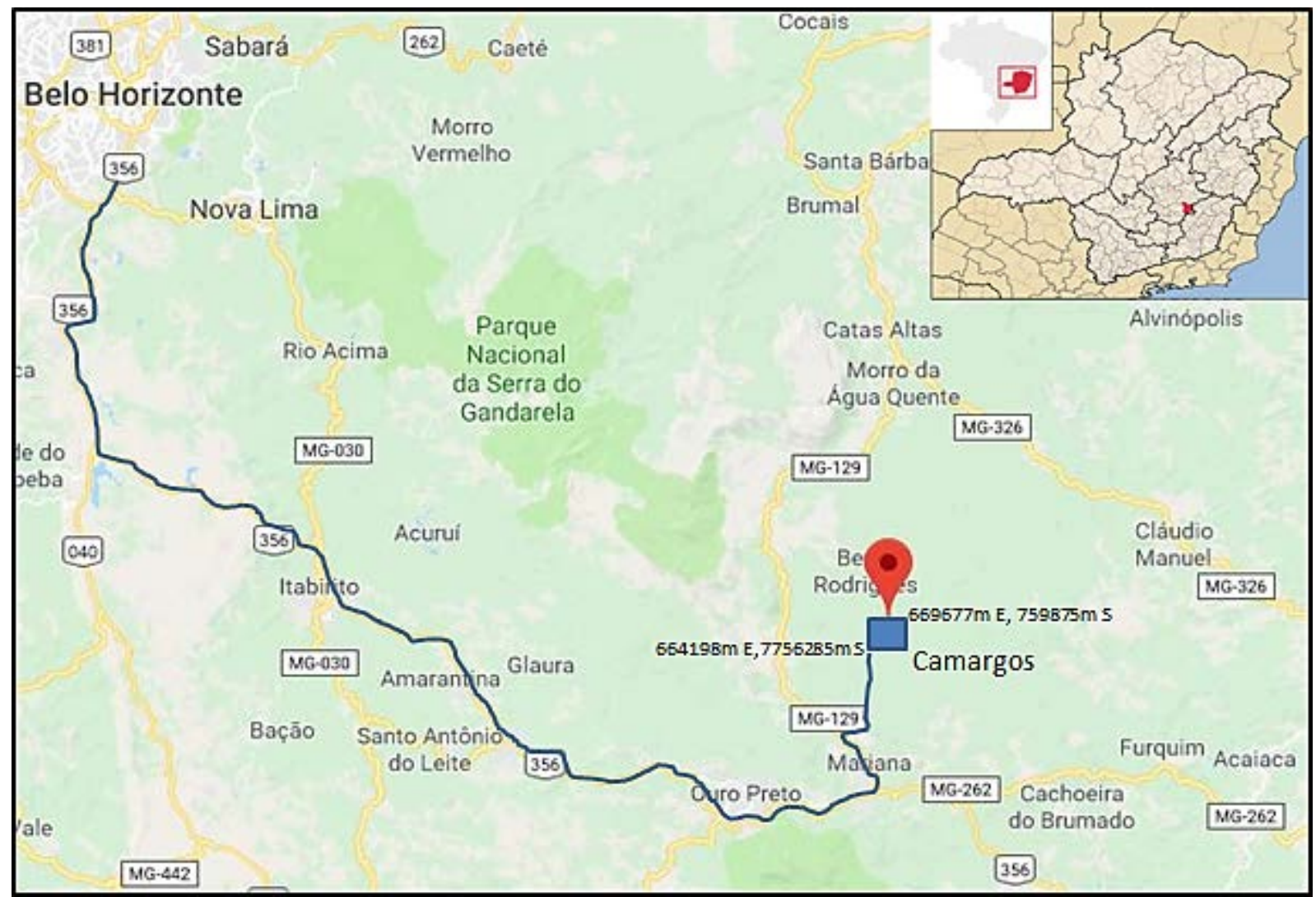

Figura 1 - Localização da área em estudo. A referência é a capital do estado de Minas Gerais, Belo Horizonte. A partir dela, segue-se pela BR-356 até Ouro Preto e depois a MG-129 até a saída de Mariana para Antônio Pereira. Por fim, segue-se à direita (altura da Mina Del Rei) por $20 \mathrm{~km}$ em estrada de terra (Estrada Real). Modificado de Google Maps (2018).

Em adição a este cenário de riqueza mineral, visto a escassez de dados da literatura geológica sobre a região, com destaque ao mapeamento geológico de Dias \& Kaneko (1993) e que, atualmente, bancos de dados geofísicos aerolevantados são disponibilizados, gratuitamente, pelo Serviço Geológico do Brasil CPRM e Companhia de Desenvolvimento de Minas Gerais - CODEMIG, torna-se interessante a análise geofísica integrada aos dados geológicos de literatura e aos detalhes de levantamentos de campo.

De acordo com Carneiro \& Barbosa (2008), em regiões de solos mais desenvolvidos como a de Camargos, a cobertura de solo pode impossibilitar a observação de detalhes geoestruturais e litológicos. Assim, no sentido de se investigar esses detalhes, diversos estudos têm gerado contribuições significativas com a utilização dos métodos empregados neste trabalho, que são a magnetometria e a radiometria (Blum et al., 2001; Teixeira et al., 2006; Carvalho, 2006; Queiroz, 2012; Cardoso, 2016).
A magnetometria consiste na medição de pequenas variações do campo magnético terrestre em consequência da distribuição heterogênea das rochas magnetizadas. Com isso, é possível delimitar os principais lineamentos e fontes com minerais ferromagnéticos, aflorantes ou subaflorantes (Carneiro \& Barbosa, 2008).

A radiometria investiga, em superfície, os contrastes laterais de rochas distintas pela variação de três isótopos principais (elementos de maior interesse de exploração radiométrica), urânio $\left({ }^{238} \mathrm{U}\right)$, tório $\left({ }^{232} \mathrm{Th}\right)$ e potássio $\left({ }^{40} \mathrm{~K}\right)$, cuja propriedade a se analisar é a emissão natural de raios gama pelos mesmos (Telford et al., 1990; Kearey et al., 2002; Milson, 2003).

Neste interim, este trabalho objetiva, por meio do processamento de banco de dados aerolevantados dos métodos supracitados, em escala 1:20.000, interpretar e discutir as implicações geológicas sobre os lineamentos e as fácies geofísicas definidas com balizamento nos dados de literatura e nos levantados em campo, com foco à análise geoestrutural, litológica e geoeconômica da área em estudo. 


\section{CONTEXTUALIZAÇÃO GEOLÓGICA}

A região de Camargos está situada na borda leste do Quadrilátero Ferrífero - QF que trata de região montanhosa, de grande beleza natural e rica em depósitos minerais. Em mapa, o QF possui uma forma, aproximadamente, retangular, definida pela orientação de um conjunto de serras, as quais representam grandes estruturas dobradas, do tipo sinclinal, anticlinal e homoclinal (Almeida \& Hasui, 1984; Endo, 1988; Uhlein \& Noce, 2012). O QF ocupa uma área de, aproximadamente, 7.190 $\mathrm{km}^{2}$ na porção central do estado de Minas Gerais e se encontra, parcialmente, inserido no extremo sudeste do Cráton do São Francisco (Almeida, 1977) e, parcialmente, no Orógeno Araçuaí (Almeida, 1977), de idade Brasiliana (Reis et al., 2002).

Em suma, o QF é caracterizado por sequências supracrustais metamórficas neoarqueanas e proterozoicas e sedimentos recentes assentados sobre o embasamento cristalino. Assim, conforme Roeser \& Roeser (2010), o embasamento cristalino é composto por gnaisses tonalítico-graníticos de idade arqueana (>2,7 Ga). Da base para o topo, as sequências supracrustais são: Supergrupo Rio das
Velhas que trata de sequência tipo greenstone belt de idade arqueana (Carneiro et al., 1998), Supergrupo Minas e Grupo Itacolomi que tratam de rochas metassedimentares paleoproterozoicas (Dorr, 1969; Machado et al., 1996; Alkmim \& Marshak, 1998).

A borda leste do QF, onde está situada a área em estudo, se constitui na fração do Orógeno Araçuaí caracterizado pela presença de obstáculos de antepaís oriundos da ascenção de domos do embasamento, que se deu após o colapso da cadeia Transamazônica (Marshak et al., 1992; Endo, 1997; Alkmim \& Marshak, 1998). Para Filho \& Fonseca (2001), os domos influenciaram a formação de dois sistemas de falhas que se articulam: Fundão-Cambotas (Dorr, 1969; Endo \& Fonseca, 1992) e Água Quente (Dorr, 1969; Maxwell, 1972).

Nestes sistemas estão inseridos o Homoclinal de Camargos (HC) e o Horst de Camargos (HtC) os quais estão relacionados diretamente à área em estudo, bem como, o Sinclinal de Santa Rita (SSR), a Nappe de Ouro Fino (NFO), dentre outras estruturas (Figura 2).

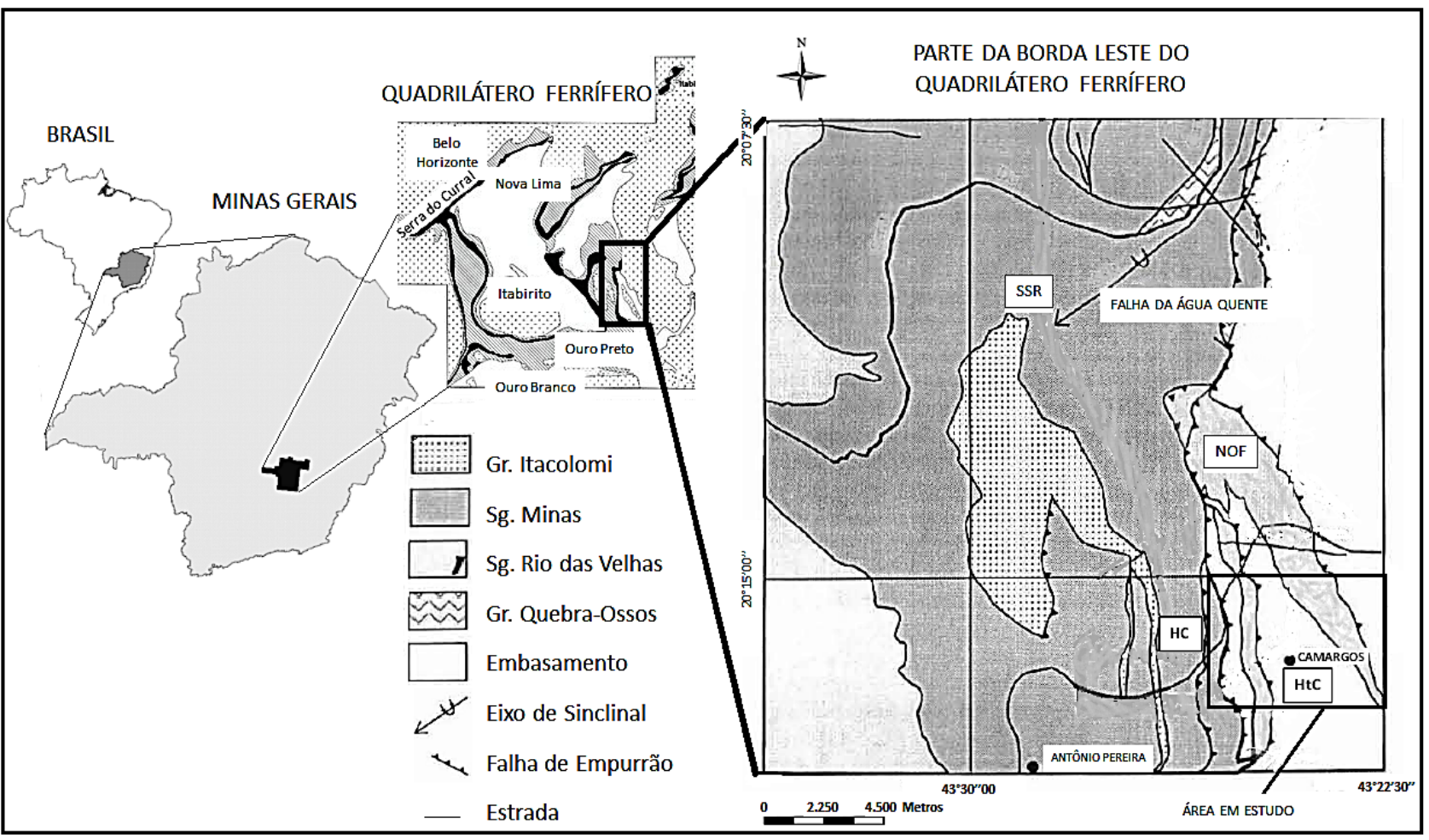

Figura 2 - Esquema de parte da borda leste do QF com enfoque em três estruturas: feições de falhas de empurrão nas direções N-S e NW-SE dos sistemas da Água Quente e de Fundão-Cambotas; Homoclinal de Camargos (HC) com a inversão das sequências dos supergrupos Rio das Velhas e Minas; e o embasamento exposto pelo Horst de Camargos (HtC). Modificado de Filho \& Fonseca (2001).

Segundo Filho \& Fonseca (2001), o Homoclinal de Camargos é caracterizado pela estratigrafia invertida e ausência do Grupo Caraça (Dorr et al.,
1957; Wallace, 1958; Maxwell, 1958). Faz contato a leste com os gnaisses por falha de empurrão (Falha da Água Quente) e a oeste, com as escamas 
tectônicas de falhas de empurrão, envolvendo as litologias do Grupo Piracicaba (Dorr, 1969). Constitui a estrutura de ligação entre os sistemas de falhas Fundão-Cambotas e Água Quente, adjacente ao flanco nordeste do Anticlinal de Mariana (Nalini Jr, 1993). O Horst de Camargos é formado pelos gnaisses com vários cordões de quartzito conglomerático do Grupo Maquiné (Derby, 1906; Dorr, 1969). O mapa geológico da área em estudo, em escala 1:20.000, é apresentado na figura 3 e a litoestratigrafia, segundo Dias \& Kaneko (1993), é estruturada da base para o topo da seguinte forma: Embasamento Cristalino Mesoarqueano composto por gnaisses, por vezes, milonitizados; Supergrupo
Rio das Velhas, idade Neoarqueana (xistos Indiviso / Grupo Nova Lima e quartzitos conglomeráticos - Indiviso / Grupo Maquiné) e Supergrupo Minas, idade Proterozoica (itabirito Formação Cauê / Grupo Itabira e quartzito ferruginoso intercalado a filito prateado Formação Cercadinho / Grupo Piracicaba). Canga e sedimentos recentes completam o topo da estratigrafia.

A foliação metamórfica varia. A atitude média na porção mais a oeste é de, aproximadamente, NS / $30^{\circ} \mathrm{E}$ e, na porção mais a leste, de $\mathrm{N} 25^{\circ} \mathrm{W}$ / $\mathrm{N} 60^{\circ} \mathrm{E}$. É ressaltada no mapa a observação de uma falha de direção NE-SW a nordeste do vilarejo.

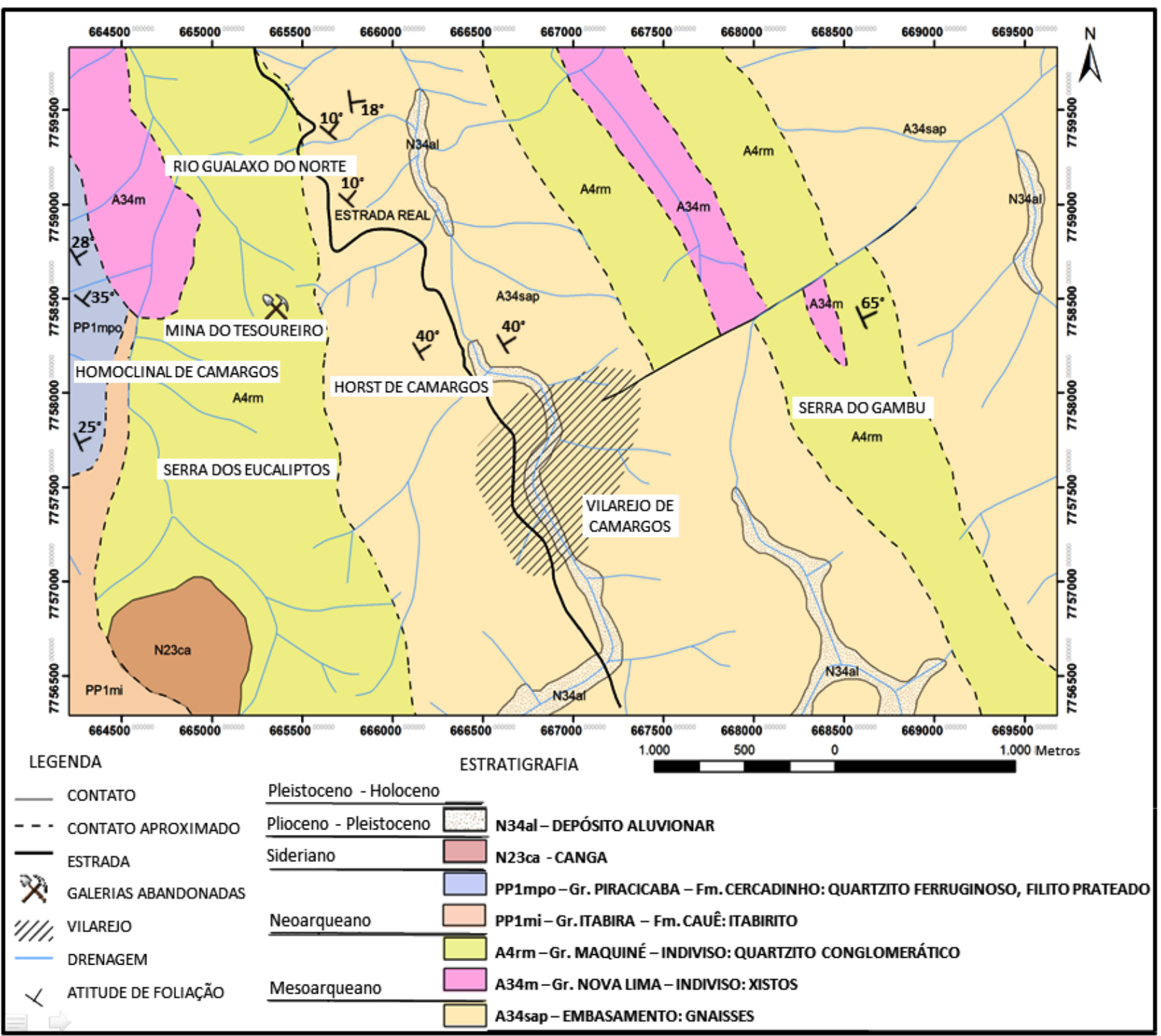

Figura 3 - Mapa geológico da área em estudo. Modificado de Dias \& Kaneko (1993).

O vilarejo de Camargos está assentado no fundo de um vale de trend $\mathrm{N}-\mathrm{NW}$, onde está encaixado o embasamento, mas, devido ao espesso manto de alteração, são observados poucos afloramentos do mesmo em campo. O vilarejo foi desenvolvido aos arredores de depósitos aluvionares do córrego principal, em um cenário de planície de inundação confinada.

O vale é limitado por duas serras: a leste está situada a Serra do Gambu (alinhada na direção NW-SE) sustentada pelos quartzitos do Grupo Maquiné, bem como, são observadas escamas 
tectônicas dos xistos do Grupo Nova Lima entre os quartzitos, e a oeste está situada uma serra sem nome que, por hora, foi denominada por Dias \& Kaneko (1993) como Serra dos Eucaliptos (alinhada na direção N-S). A oeste e em contato com a última serra, afloram sequências do Supergrupo Minas, bem como, uma cobertura de canga. No extremo nordeste da região, o embasamento também aflora.

Em termos de geologia econômica, segundo Rossi (2010), o ouro explotado da região de Camargos desde o Século XVII até o XX, é descrito na literatura como sendo dos depósitos da Serra da Boa Vista. As famosas minas históricas desta serra são Quebra Osso, Cata Preta, Ouro fino, Tesoureiro, dentre outros garimpos menores (Ferrand, 1894; Freyberg, 1934; Calógeras, 1938; Moraes \& Barbosa, 1939). Apenas as partes rasas dos depósitos foram exploradas devido às limitações tecnológicas no período de exploração.

Das minas supracitadas, a que está situada na região de Camargos e é marcada no mapa geológico (apresentado anteriormente na figura 3), é a Mina do Tesoureiro que trata de galerias antigas de exploração de ouro na porção noroeste da área em estudo.

Para Ferrand (1894), nesta mina eram explorados xistos com quartzo e pirita. Para Heineck \& Silva (1993), suas mineralizações de quartzo sulfetado aurífero estão associados a conglomerados e quartzitos ou no contato destes com gnaisses e xistos. Rossi (2010) descreve que a mineralização está associada a metaconglomerados de seixos de quartzitos, metachert e itabirito, quartzitos micáceos miloníticos e veios de quartzo, em ambiente de paleoplacer.

Atualmente, alguns moradores mineram ouro secundário de forma manual com técnicas rudimentares herdadas da antiga mineração em pequenos garimpos no córrego principal que atravessa o vilarejo, e no Rio Gualaxo do Norte (discriminado anteriormente na figura 3).

\section{MATERIAIS E MÉTODOS}

O banco de dados aerolevantados de magnetometria e radiometria utilizado neste trabalho foi disponibilizado gratuitamente pela CPRM / CODEMIG. Trata-se da Área 2 que é subdividida em dois blocos: leste e oeste. A região de estudo está enquadrada no Bloco Leste. Para ambos os métodos, o levantamento foi aéreo e, segundo relatório da LASA (2001), a altura e a velocidade de voo foi $100 \mathrm{~m}$ e $200 \mathrm{~km} / \mathrm{h}$, o espaçamento entre as linhas de voo foi de $250 \mathrm{~m}$, o espaçamento entre as linhas de controle foi de $2.500 \mathrm{~m}$, a direção das linhas de voo foi $\mathrm{N} 30^{\circ} \mathrm{W}$, e a direção das linhas de controle foi $\mathrm{N} 60^{\circ} \mathrm{E}$. A velocidade de levantamento magnetométrico foi de 10 medidas / s e o instrumental utilizado foi o magnetômetro com sensor do tipo vapor de césio, Geometrics G-822A, com resolução de 0,001 nT. Na radiometria a velocidade de levantamento foi de 1 medida / s e o instrumental utilizado foi o gamaespectrômetro Exploranium GR-820, de 256 canais espectrais.

Os dados do Campo Magnético Anômalo, corrigidos do International Geomagnetic Reference Field - IGRF, foram interpolados através de mínima curvatura, em uma malha regular de $300 \mathrm{~m}$. Foram investigados na magnetometria, além do Campo Anômalo, seus produtos de derivação (Gradiente Vertical: $1^{\mathrm{a}}$ e $2^{\mathrm{a}}$ derivada em $\mathrm{z}$ para análise de anomalias mais superficiais / residuais, Gradientes Horizontais: $1^{a}$ derivada em $\mathrm{x}$ para análise de anomalias estruturadas na direção N-S e $1^{\text {a }}$ derivada em y para análise de estruturação E-W), a Amplitude do Sinal Analítico - ASA para análise das anomalias ao entorno do corpo que lhe deu origem e a Derivada da Amplitude do Sinal Analítico - DASA para refinar a interpretação regional.

$\mathrm{Na}$ radiometria foram analisados os canais ${ }^{232} \mathrm{Th},{ }^{238} \mathrm{U}$ e ${ }^{40} \mathrm{~K}$ e Contagem Total, para comparar e integrar as anomalias entre os mapas temáticos objetivando um modelo que distinga as litologias da área em estudo, bem como, para investigar o arcabouço estrutural regional raso em suporte à análise dos dados magnéticos.

Em ambos os métodos, os lineamentos interpretados foram tratados estatisticamente no software GeoRose (Yong Technology Inc., 2014), com a finalidade de facilitar a discussão geológica-estrutural. O mapa Razão ${ }^{238} \mathrm{U} /{ }^{232} \mathrm{Th}$ foi gerado objetivando discutir as idades relativas entre as rochas da região, uma vez que a desintegração dos radioisótopos pais de ${ }^{238} \mathrm{U}$ para radioisótopos filhos de ${ }^{232} \mathrm{Th}$ trazem implicações neste sentido. $\mathrm{O}$ mapa Fator $\mathrm{F}$ foi gerado objetivando a discussão das implicações geoeconômicas.

Em adição, trabalhos de campo foram realizados para aferição de estruturas, verificação de afloramentos e de ocorrências de minério de 
ouro nos locais com potencial de ocorrência definidos neste trabalho, interpretados pela análise geofísica, bem como, verificação de ocorrência do minério nos depósitos aluvionares.

\section{RESULTADOS DO PROCESSAMENTO DE DADOS}

O fluxograma com a apresentação das etapas que vão desde a importação do banco de dados até a geração dos mapas temáticos magnetométricos e radiométricos, é apresentado na figura 4.

Acerca dos mapas magnetométricos, inicialmente, foi gerado o Campo Magnético Anômalo cujos valores apresentados estão na ordem de nT. A partir dele foram gerados os mapas ASA e gradientes Horizontais (dx e dy) e Vertical (dz), todos na ordem de nT/m. Por fim, foram gerados o Campo Residual $\left(\mathrm{d}^{2} \mathrm{z}\right)$ e $\mathrm{o}$ DASA, ambos na ordem de $\mathrm{nT} / \mathrm{m}^{2}$.

Acerca dos mapas radiométricos, foi gerado o mapa de cada canal ${ }^{238} \mathrm{U},{ }^{232} \mathrm{Th}$ e ${ }^{40} \mathrm{~K}$, o mapa Contagem Total e o mapa Fator F, na grandeza de cintilações por segundo - cps, bem como, o mapa Razão ${ }^{238} \mathrm{U} /{ }^{232} \mathrm{Th}$.

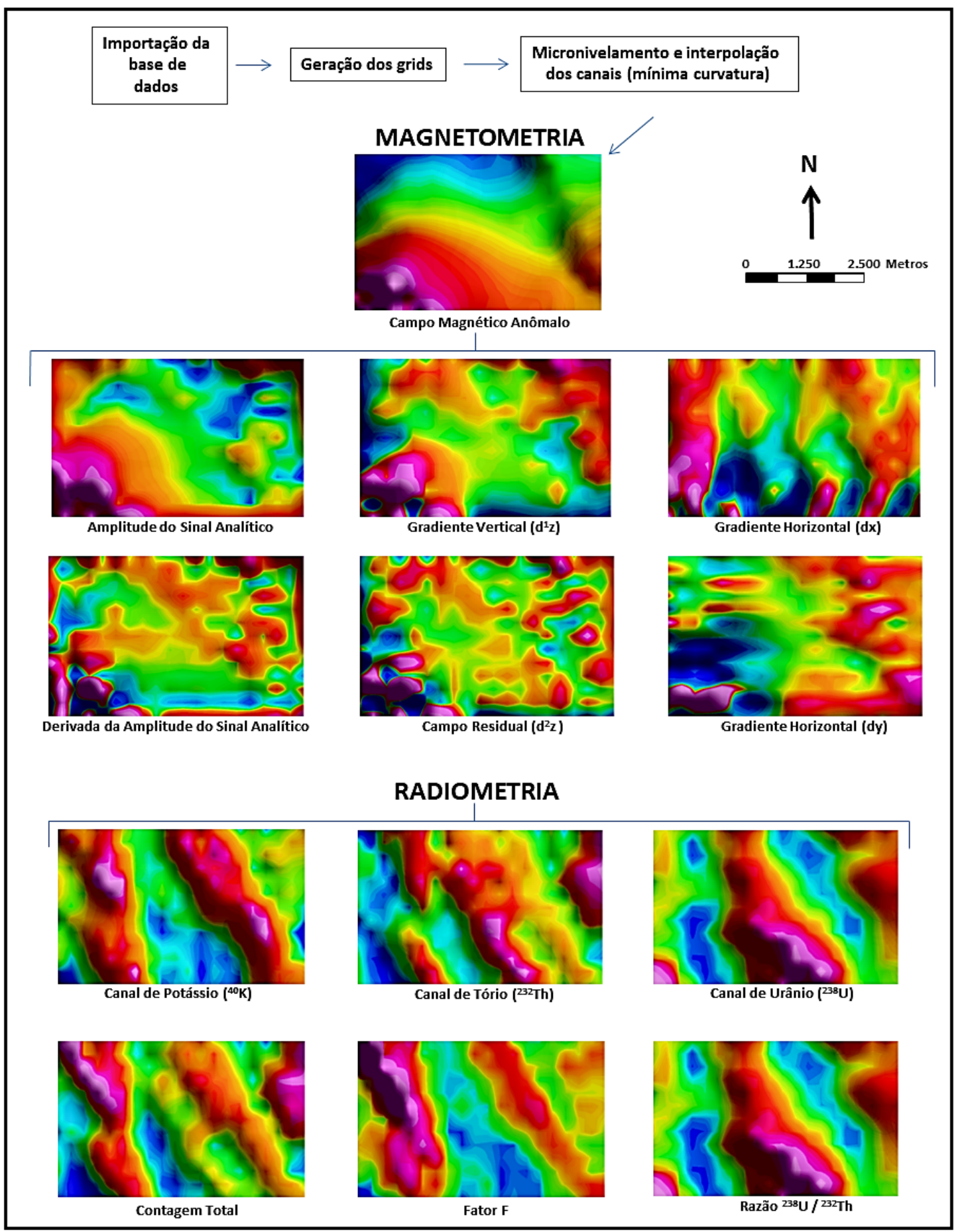

Figura 4 - Fluxograma das etapas de processamento dos dados aerolevantados de magnetometria e radiometria. 
Na figura 5 é apresentado o mapa DASA com a sobreposição dos lineamentos magnéticos interpretados.

É ressaltado que todos os mapas magnetométricos, uma vez georreferenciados, foram sobrepostos uns aos outros e analisados um a um para se chegar a este resultado. Os lineamentos foram tratados estatisticamente e apresentados na forma de rosa de lineamentos.

Na figura 6 são apresentados os lineamentos radiométricos interpretados sobrepostos ao mapa Canal ${ }^{40} \mathrm{~K}$, por meio da análise de todos os mapas radiométricos supracitados, analogamente à metodologia para o alcance do resultado da magnetometria. Em adição, são discriminadas cinco radiofáceis definidas neste trabalho que serão descritas a frente, bem como, serão discutidas suas implicações geológicas.

As cinco radiofáceis estão delimitadas no mapa Canal ${ }^{40} \mathrm{~K}$ baseando-se no conteúdo de cada radioelemento supracitado em cada litologia. A figura 7 discrimina as radiofáceis. Para facilitar esta discriminação e, já que o resultado trata de mapas colorpédicos, foi adotada neste trabalho a distinção das anomalias por cor (s), observada a respectiva correspondência à magnitude das faixas de valor nos mapas: cor azul - magnitude baixa; verde ao amarelo - intermediária; laranja ao vermelho alta; e magenta - muito alta.

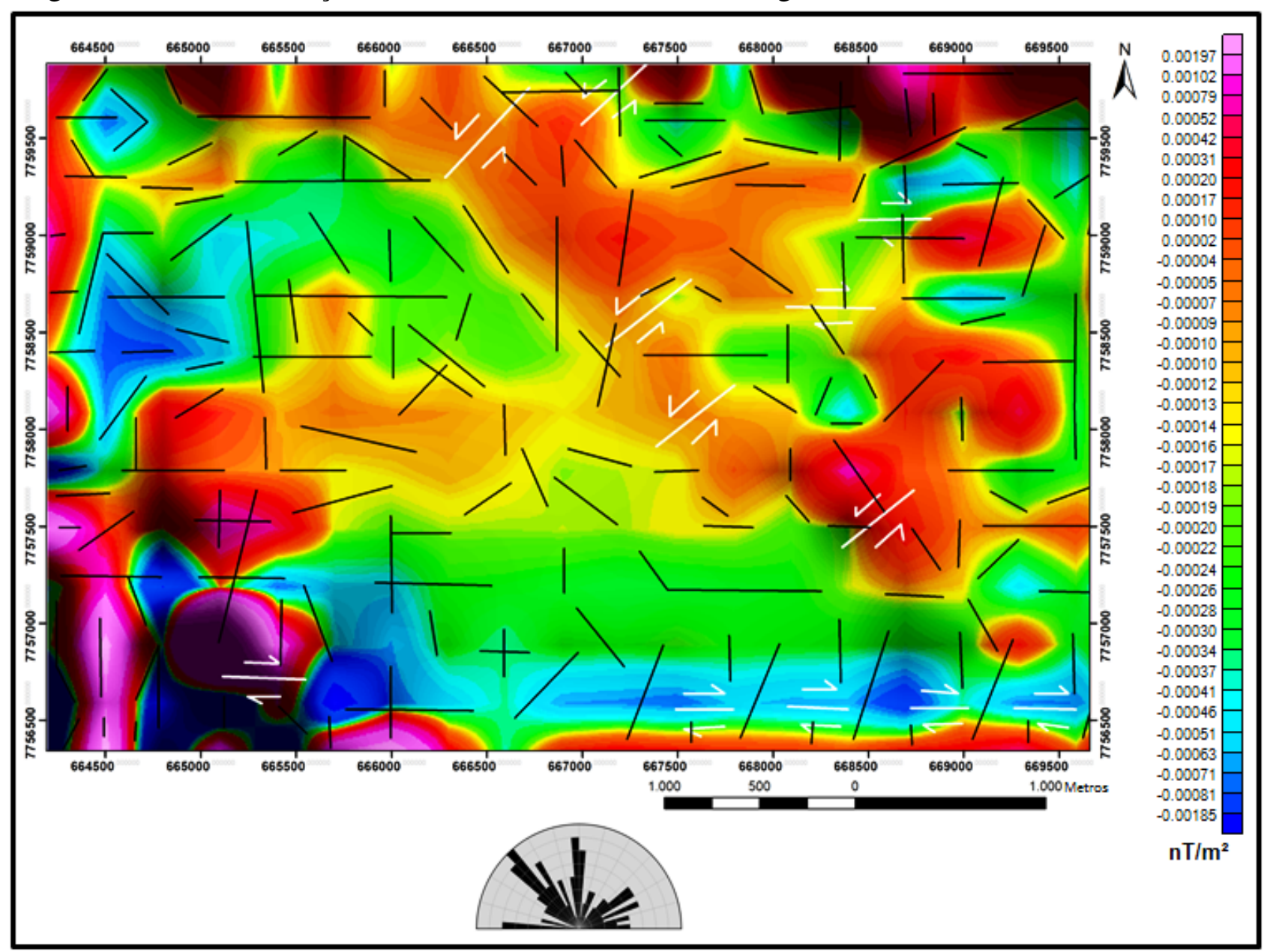

Figura 5 - Apresentação dos lineamentos magnéticos interpretados sobre o mapa DASA. Os lineamentos em preto e em branco representam feições sem e com movimento, respectivamente. É observada a distribuição estatística na rosa de lineamentos com estruturações mais fortes nas direções N-S, E-W, $30^{\circ}-50^{\circ} \mathrm{NW}$ e $45^{\circ}-55^{\circ} \mathrm{NE}$.

\section{DISCUSSÕES DOS RESULTADOS}

Considerando a dificuldade de interpretação do Campo Anômalo, devido ao seu caráter dipolar, recorre-se à redução ao pólo, mas, segundo Swain (1976), ela não deve ser aplicada em baixas latitudes $\left(<25^{\circ}\right)$ e em terrenos de alta residência crustal, que é o caso dos terrenos da área em estudo. A saída é utilizar ASA, por discriminar a anomalia ao redor do corpo que lhe deu origem, o que mais se aproximaria às interpretações de um mapa de natureza monopolar.

Para acurar as interpretações, neste trabalho recorreu-se à derivação de ASA, onde foram sobrepostos os lineamentos interpretados de 
todos os mapas magnéticos e que, de acordo com Fairhead \& Maus (2003), possibilita separações eficientes das anomalias causadas por estruturas que estão muito próximas. Por outro lado, no caso da utilização da radiometria, o mapa cujo desenho estrutural mais se aproxima ao mapa geológico da região é o Canal ${ }^{40} \mathrm{~K}$, no qual se observa mais claramente os lineamentos interpretados, bem como, as radiofáceis definidas, sendo o mais apropriado para sobreposição das interpretações de todos os mapas radiométricos.

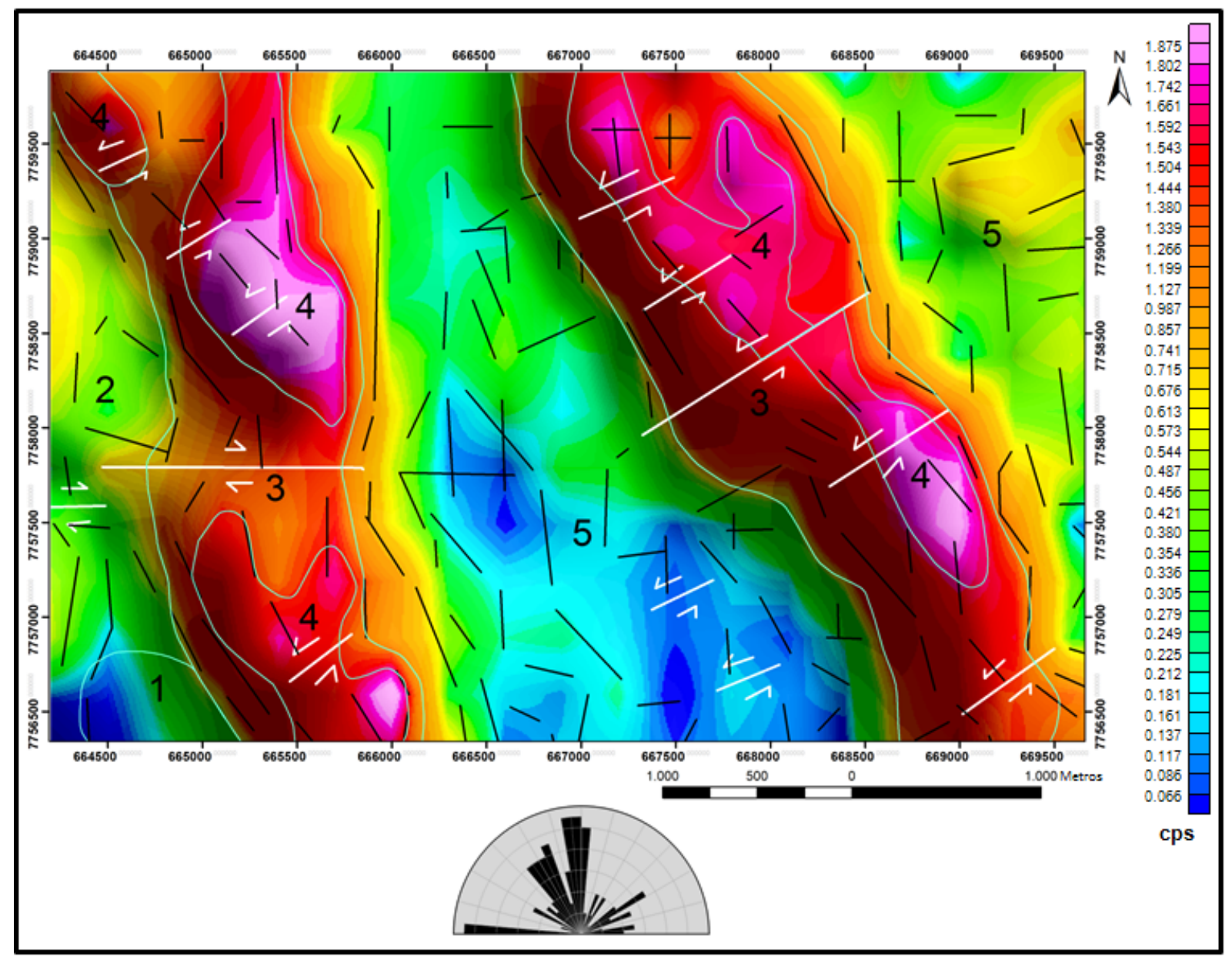

Figura 6 - Apresentação dos lineamentos radiométricos interpretados sobre o mapa Canal ${ }^{40} \mathrm{~K}$. Os lineamentos em preto e em branco representam feições sem e com movimento, respectivamente. É observada a distribuição estatística na rosa de lineamentos com estruturações mais fortes nas direções $\mathrm{N}-\mathrm{S}, \mathrm{E}-\mathrm{W}, 25^{\circ}-40^{\circ} \mathrm{NW}$ e $50^{\circ}-65^{\circ} \mathrm{NE}$. Além disso, estão discriminadas cinco radiofáceis distintas.

\begin{tabular}{|c|c|c|c|c|c|c|}
\hline \multirow[b]{2}{*}{ RADIOFÁCEIS } & \multirow[b]{2}{*}{ LITOLOGIA } & \multirow[b]{2}{*}{ UNIDADE } & \multicolumn{3}{|c|}{ RADIOISÓTOPOS } & \multirow[b]{2}{*}{$\begin{array}{c}\text { CONTAGEM } \\
\text { TOTAL }\end{array}$} \\
\hline & & & ${ }^{40} \mathrm{~K}$ & ${ }^{238} \mathbf{U}$ & ${ }^{232} \mathrm{Th}$ & \\
\hline 1 & Canga & $\begin{array}{l}\text { Sedimentos } \\
\text { Recentes }\end{array}$ & baixa & intermediária & baixa & baixa \\
\hline 2 & $\begin{array}{c}\text { Filito e } \\
\text { Quartzito } \\
\text { Ferruginoso } \\
\end{array}$ & $\begin{array}{c}\text { Gr. } \\
\text { Piracicaba }\end{array}$ & intermediária & intermediária & $\begin{array}{c}\text { baixa a } \\
\text { intermediária }\end{array}$ & $\begin{array}{c}\text { baixa a } \\
\text { intermediária }\end{array}$ \\
\hline 2 & Itabirito & Gr. Itabira & intermediária & intermediária & \begin{tabular}{|c|} 
baixa a \\
intermediária \\
\end{tabular} & $\begin{array}{c}\text { baixa a } \\
\text { intermediária }\end{array}$ \\
\hline 3 & $\begin{array}{c}\text { Quartzitos } \\
\text { Conglomeráticos } \\
\end{array}$ & Gr. Maquiné & alta & intermediária & alta & $\begin{array}{c}\text { alta a } \\
\text { intermediária }\end{array}$ \\
\hline 4 & Xistos & $\begin{array}{l}\text { Gr. Nova } \\
\text { Lima }\end{array}$ & muito alta & baixa & muito alta & $\begin{array}{c}\text { alta a muito } \\
\text { alta }\end{array}$ \\
\hline 5 & Gnaisses & Embasamento & $\begin{array}{c}\text { baixa a } \\
\text { intermediária }\end{array}$ & $\begin{array}{c}\text { alta a muito } \\
\text { alta }\end{array}$ & $\begin{array}{c}\text { baixa a } \\
\text { muito alta }\end{array}$ & $\begin{array}{c}\text { baixa a } \\
\text { intermediária }\end{array}$ \\
\hline
\end{tabular}

Figura 7 - Relação do conteúdo dos radioisótopos ${ }^{40} \mathrm{~K},{ }^{238} \mathrm{U}$ e ${ }^{232} \mathrm{Th}$ em cada litologia na definição das cinco radiofáceis distintas. 
A partir da análise da rosa de lineamentos magnéticos são observados fortes trends N/S e $30^{\circ}-50^{\circ} \mathrm{NW}$ dos quais é observado certo paralelismo em relação às direções da foliação metamórfica regional. Há lineamentos magnéticos nas direções E/W e $45^{\circ}-55^{\circ} \mathrm{NE}$ que, por vezes, apresentam cinemática indicando deslocamento relativo entre anomalias o que caracteriza um domínio de falhas direcionais no arcabouço estrutural da região. Desta forma, são discriminadas neste trabalho duas famílias de falhas direcionais: F1 na direção E-W de cinemática dextral e F2 na direção NE-SW de cinemática sinistral. As feições com indicação de seus respectivos movimentos são discriminadas na figura 5 que foi apresentada anteriormente.

Os mapas em que se observa mais claramente essas feições cinemáticas são o ASA, o DASA, o Gradiente Horizontal em x e o Campo Residual. Neste sentido, a família F1 é observada na porção nordeste do mapa ASA. Nesta porção as famílias F1 e F2 são observadas nos mapas DASA e Campo Residual. Na porção sudeste do mapa Gradiente Horizontal em x são observados claramente deslocamentos entre anomalias causados pelos lineamentos da família F1.

Em relação à radiometria, a partir da análise da rosa de lineamentos radiométricos são observados fortes trends N/S e $25^{\circ}-40^{\circ} \mathrm{NW}$ dos quais também é observado certo paralelismo em relação às direções da foliação metamórfica. Há lineamentos radiométricos nas direções E-W e $50^{\circ}-65^{\circ} \mathrm{NE}$ que, por vezes, também apresentam deslocamento relativo entre anomalias o que caracteriza aquele domínio de falhas direcionais no arcabouço estrutural da região, interpretado na magnetometria.

Desta forma, fortalecendo a interpretação das falhas direcionais F1 e F2, na Radiometria são observados deslocamentos de grandes áreas anômalas. Os mapas em que estes deslocamentos são mais claramente visíveis são Contagem Total, Canal ${ }^{40} \mathrm{~K}$ e Canal ${ }^{232} \mathrm{Th}$. A família F1 é observada com maior predominância nos mapas magnetométricos enquanto a F2, nos radiométricos.

Um grande lineamento da família F2 é observado na porção leste do mapa geológico e em campo, esboçando um extenso rejeito de falha entre 600 e $700 \mathrm{~m}$ de comprimento que intercepta a Serra do Gambu. A maioria dos lineamentos aferidos em campo foram observados nas serras onde afloram os quartzitos do Grupo Maquiné. Como a porção norte da região foi coberta pela lama oriunda do rompimento da barragem, fato inicialmente apresentado neste trabalho e, até então serviços têm sido realizados para recuperação, há certa limitação de acesso aos afloramentos. Desta forma, é apresentada a distribuição estatística na rosa de lineamentos da direção de 50 descontinuidades geoestruturais aferidas na porção mais a sul das serras, conforme a figura 8 . São observados fortes trends nas direções N-S, E-W, $20^{\circ}-30^{\circ} \mathrm{NW}$ e $50^{\circ}-65^{\circ} \mathrm{NE}$. Assim, a distribuição dos lineamentos geofísicos tem boa aproximação à distribuição dos dados aferidos em campo. Em adição, em uma pequena cachoeira, denominada pelo vilarejo como Cachoeira de Camargos, é possível observar afloramentos dos gnaisses e alguns lineamentos paralelos aos interpretados na geofísica. Partes migmatizadas e outras milonitizadas também são observadas. A milonitização reforça a interpretação geofísica da presença das zonas de cisalhamento na região.

Os lineamentos geofísicos na direção N-S, certamente, têm relação às expressões de falhas de empurrão da Água Quente, as quais separam o Horst de Camargos da Homoclinal homônima. Em adição, as radiofáceis as quais serão explanadas a seguir ajudam a mostrar a separação destas duas estruturas.

As cinco radiofáceis definidas: 1, 2, 3, 4 e 5, estão relacionadas, respectivamente, às litologias das unidades estratigráficas: Sedimentos Recentes; grupos Piracicaba e Itabira; Grupo Maquiné; Grupo Nova Lima; e Embasamento.

Radiofáceis 1: está relacionada à canga a qual está exibindo anomalia baixa de ${ }^{232} \mathrm{Th}$, por tratarse do tipo de canga definida por Dorr (1964) como estrutural, ou seja, itabirito intemperizado. Logo, ele é isento de detritos que poderiam apresentar conteúdo de ${ }^{232} \mathrm{Th}$ e ${ }^{238} \mathrm{U}$. O conteúdo de ${ }^{40} \mathrm{~K}$ é baixo o que já era esperado para este tipo de litologia.

Radiofáceis 2: está relacionada ao quartzito ferruginoso intercalado ao filito prateado e ao itabirito os quais apresentam nos mapas grande similaridade no conteúdo dos radioisótopos considerados, de forma que as anomalias variam de baixas a intermediárias. Vale ressaltar que estas litologias ferríferas, as quais estão situadas na porção oeste da área em estudo, exibem assinatura de magnitude relativamente alta nos mapas magnetométricos ASA, DASA, Gradiente 
Vertical e Campo Residual, contrastando com as demais litologias.

Radiofáceis 3: está relacionada ao quartzito conglomerático o qual apresenta anomalias altas de ${ }^{40} \mathrm{~K}$ e ${ }^{232} \mathrm{Th}$. Em relação ao ${ }^{40} \mathrm{~K}$, a explicação está na mineralogia que inclui cerca de $40 \%$ de mica branca e ao enriquecimento hidrotermal (assunto que será abordado a frente tocante à geologia econômica). Em relação ao ${ }^{232} \mathrm{Th}$, a explicação deve estar na diagênese de seu protólito que pode ter incluído minerais como a monazita na deposição de sedimentos para sua formação. O conteúdo de ${ }^{238} \mathrm{U}$ exibe anomalia intermediária que pode estar relacionada à presença de uraninita.

Radiofáceis 4: está relacionada aos xistos os quais exibem anomalias de ${ }^{40} \mathrm{~K}$ e ${ }^{232} \mathrm{Th}$ muito altas 0 que se relaciona à composição mineralógica de cerca de $50 \%$ de mica branca, bem como, de enriquecimento hidrotermal no caso do ${ }^{40} \mathrm{~K}$ e, no caso do ${ }^{232} \mathrm{Th}$, da argilosidade, já que os xistos são litologias metapelíticas, conforme explicado por Ellis \& Singer (2008, segundo Ferreira et al., 2010), que em virtude da capacidade de troca catiônica - CTC, os minerais de argila retêm elementos-traço como o Th, insolúvel e de mobilidade baixa. A anomalia de ${ }^{238} \mathrm{U}$ é intermediária nestas litologias.

Radiofáceis 5: está relacionada aos gnaisses os quais exibem conteúdo radiogênico muito variado. O destaque é para $0^{238} \mathrm{U}$ cujas anomalias chegam a ser consideradas a até muito altas. $\mathrm{O}$ conteúdo de ${ }^{232} \mathrm{Th}$ está variando muito, certamente, devido ora à exposição de rocha e ora, de cobertura espessa de solo. As anomalias de ${ }^{40} \mathrm{~K}$ variam de baixas à intermediárias devido à variação na composição mineralógica que inclui k-feldspatos.

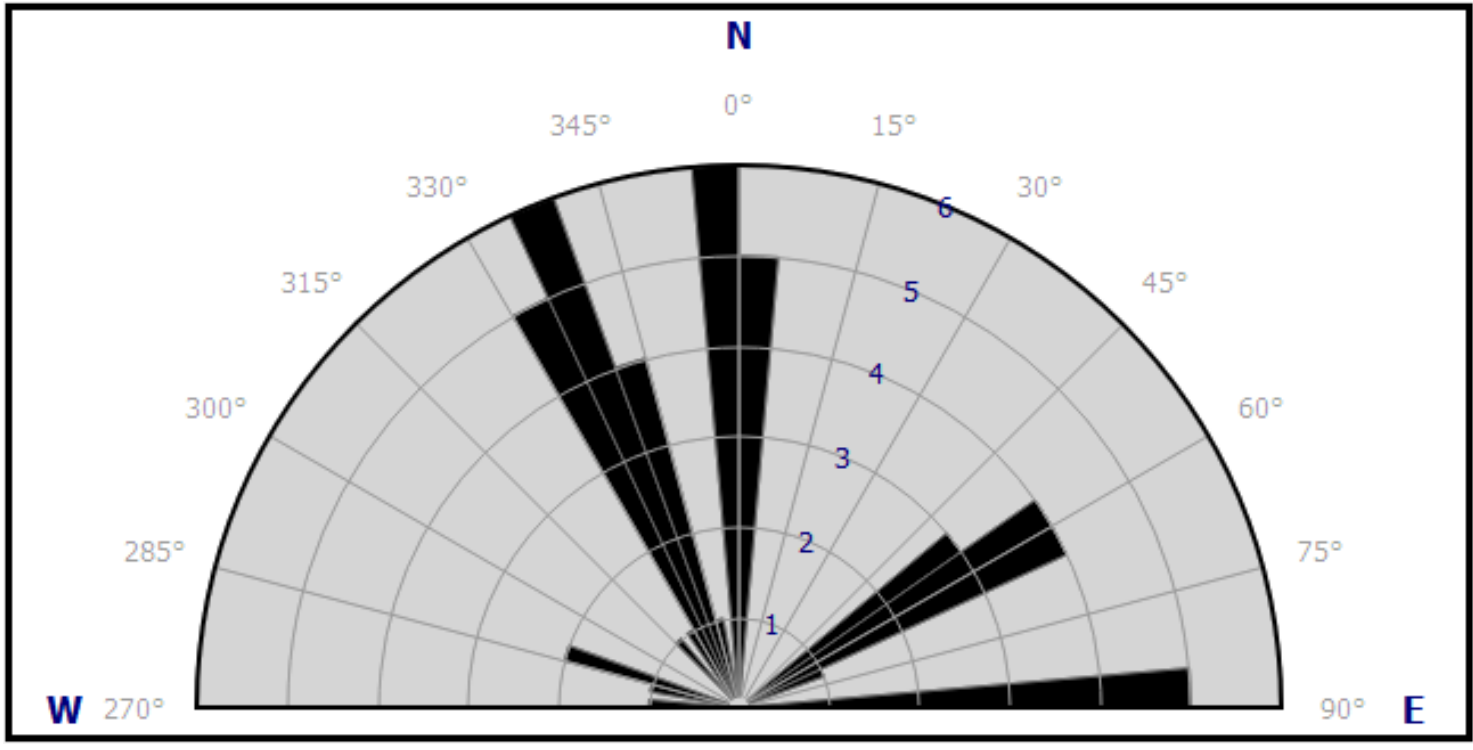

Figura 8 - Distribuição estatística na rosa de lineamentos da direção de 50 descontinuidades geoestruturais aferidas na porção mais a sul das serras da área em estudo. São observados fortes trends nas direções N-S, E-W, $20^{\circ}-30^{\circ} \mathrm{NW}$ e $50^{\circ}-$ $65^{\circ} \mathrm{NE}$.

Em relação à razão ${ }^{238} \mathrm{U} /{ }^{232} \mathrm{Th}$, quanto mais radioisótopos filhos $\left({ }^{232} \mathrm{Th}\right)$ uma rocha tiver, ou seja, quanto menor for a razão ${ }^{238} \mathrm{U} /{ }^{232} \mathrm{Th}$, mais antiga ela é, já que houve mais tempo para a desintegração dos radioisótopos pais $\left({ }^{238} \mathrm{U}\right)$. Neste sentido, na razão ${ }^{238} \mathrm{U} /{ }^{232} \mathrm{Th}$ é percebido anomalia alta no Horst de Camargos, o que implica em ser causada não pelos gnaisses (o que daria baixa anomalia condizente ao desenvolvimento de mais elementos filhos, ${ }^{232} \mathrm{Th}$, que os pais, $\left.{ }^{238} \mathrm{U}\right)$, mas sim pelo espesso manto de alteração do mesmo. As anomalias intermediárias do extremo leste implicam em sequências mais recentes relacionadas ao Supergrupo Minas. As anomalias mais baixas estão relacionadas ao Supergrupo Rio das Velhas: em azul são as escamas tectônicas dos xistos do Grupo Nova Lima e em verde, os quartzitos do Grupo Maquiné. Assim, é observada a continuação da anomalia em azul, ou seja, os xistos, para sul, o que não é apresentado no mapa geológico. A alta anomalia no extremo sudoeste está relacionada à unidade mais recente que as outras supracitadas, que é a canga. Assim, a análise da razão ${ }^{238} \mathrm{U} /{ }^{232} \mathrm{Th}$ é relacionável à disposição espacial de inversão das camadas, o que está associado ao Homoclinal de Camargos. A identificação das radiofáceis reforça esta implicação.

Hoff et al. (2004) descrevem que o Fator F 
avalia o comportamento do ${ }^{40} \mathrm{~K}$ em relação à razão ${ }^{238} \mathrm{U} /{ }^{232} \mathrm{Th}$, onde o produto entre $\mathrm{o}$ conteúdo de ${ }^{40} \mathrm{~K}$ e o conteúdo ${ }^{238} \mathrm{U} /{ }^{232} \mathrm{Th}$, o define. Logo, pela análise do mapa Fator F, são observadas duas anomalias de trend NW-SE, uma alta (porção leste) e uma muito alta (porção oeste), delimitadas no mapa da figura 9. Trata dos pacotes de quartzitos e xistos com enriquecimento secundário de ${ }^{40} \mathrm{~K}$, o que implica em hidrotermalismo na região. Neste sentido, é observada a localização da Mina do Tesoureiro na área compreendida pela anomalia da porção oeste, o que condiz com a mineralização primária em veios hidrotermais sulfetados de quartzo relatados pela literatura. Logo, a anomalia da porção leste sugere outro alvo potencial para a exploração de ouro primário em depósito de veios hidrotermais.

Paralelamente, para avaliar o potencial de ocorrência aurífera secundária, trabalhos de prospecção em campo foram realizados e em três pontos (P1, P2 e P3) foi constatado presença de ouro, sendo que P1 está dentro da área compreendida pela anomalia do mapa Fator F da porção oeste, P2 está situado aos arredores da anomalia da porção leste e, P3, em depósito aluvionar na porção central da área em estudo. A localização dos pontos é apresentada na figura 9 .

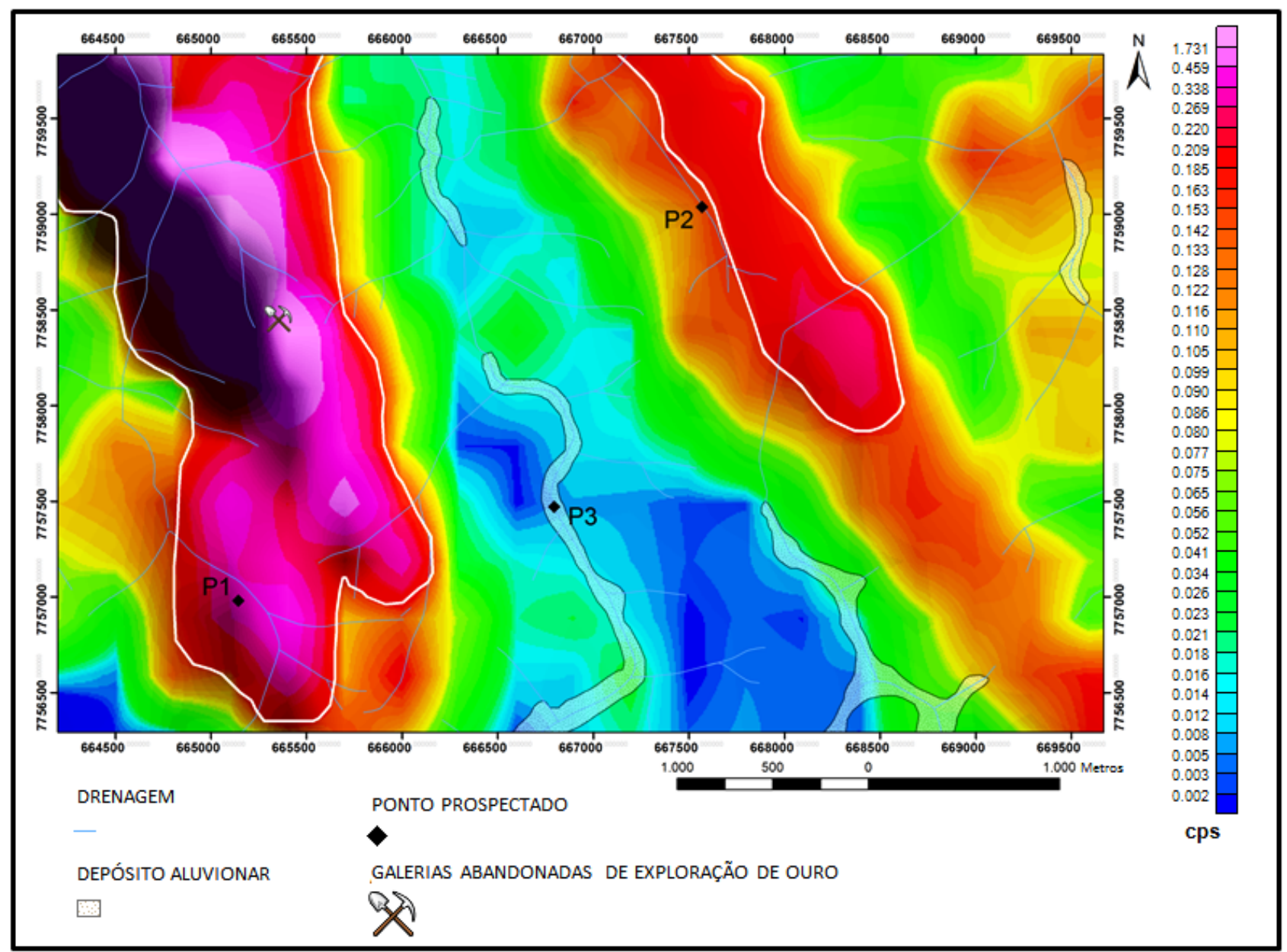

Figura 9 - Mapa Fator F com a sobreposição da rede de drenagem e dos depósitos aluvionares e os pontos de prospecção de minério de ouro. São observados os pontos P1 e P2 nas porções de anomalia alta à muito alta (delimitadas por linha cheia branca) o que implica em hidrotermalismo nos quartzitos e nos xistos do Supergrupo Rio das Velhas. O ponto P3 é observado em um depósito aluvial na porção central da região.

Em P1 foi encontrado um fragmento de goethita com sedimentos cimentados a ela, entre eles, fragmentos de rocha, quartzo e ouro. O fragmento foi prospectado em meio a material intemperizado aos arredores de um córrego da Serra dos Eucaliptos e da cobertura de canga da área em estudo. A figura 10 apresenta o fragmento, bem como, um exemplar de ouro em pepita com cerca de 0,6g com impurezas, prospectado em P2, situado na Serra do Gambu. A pepita foi encontrada junto a material cascalhoso dentro de um “caldeirão" ou "panela”, feição denominada por alguns autores, e.g. Bögli (1978), como karren que é uma expressão exocárstica que corresponde a sulcos ou ranhuras em litologias como nos quartzitos. 
Ainda na figura 10, é apresentado um concentrado de bateia com ouro em fração fina junto a opacos, fragmentos de rocha e quartzo, prospectado em P3, o qual está situado em depósito aluvionar em planície de inundação confinada onde o vilarejo foi desenvolvido.

Partindo da evidência de ocorrência de ouro em fração grosseira, certamente o mesmo deve se concentrar nos meandros dos cursos d'água, que são zonas de quebra de energia onde se acumula material mais grosseiro e denso, sobretudo naqueles do Rio Gualaxo do Norte.
Todavia, não foi possível fazer tal análise, devido à mudança forçada do curso do rio provocada pelo fluxo de detritos oriundo do rompimento da barragem.

A outra forma de ocorrência de ouro na região de Camargos, na forma de detritos constituindo os quartzitos conglomeráticos do Grupo Maquiné, cujos estudos metalogenéticos foram realizados por Rossi (2010), não foi possível ser analisada neste trabalho, devido ao alcance dos métodos geofísicos utilizados, bem como pela escala considerada que focou a análise regional.

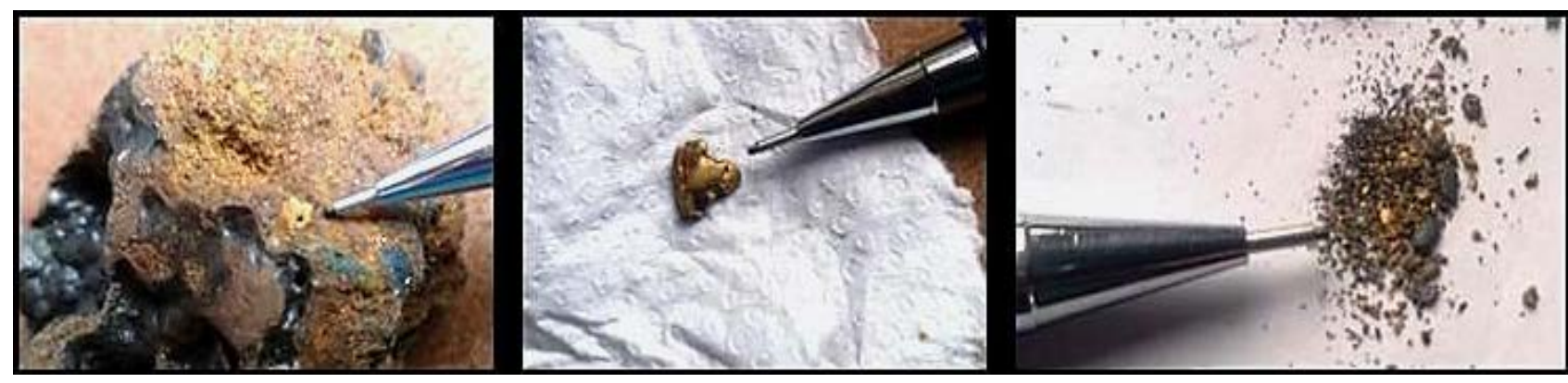

Figura 10 - Evidências do potencial aurífero da região de Camargos. À esquerda é observado fragmento de goethita com sedimento de ouro cimentado a ela, prospectado no ponto P1 (aos arredores de um córrego da Serra dos Eucaliptos e da cobertura de canga). Ao centro é observado exemplar de ouro em pepita com impurezas de coloração escura, prospectado no ponto P2 (em karren nos quartzitos, estando associado a um córrego da Serra do Gambu). À direita é observado concentrado de bateia com ouro em fração fina, prospectado em depósito aluvionar na porção central da área em estudo.

\section{CONCLUSÕES}

A análise estrutural pelos mapas magnetométricos e radiométricos com balizamento na literatura e em campo, conduziu às seguintes implicações: os lineamentos estruturais mais fortes estão nas direções NW-SE e N-S, que são paralelas às direções principais de foliação. Alguns dos lineamentos E-W e NE-SW exibem indício cinemático, o que permite definir duas famílias de falhas direcionais F1 e F2, respectivamente, sugerindo o domínio de zonas de cisalhamento, principalmente, nos pacotes quartzíticos e xistosos do Supergrupo Rio da Velhas. As feições geofísicas de direção N-S parecem corresponder também aos traços estruturais dos sistemas de falhas de empurrão da Água Quente e de Fundão-Cambotas.

As cinco radiofáceis definidas neste trabalho permitem boa distinção entre as litologias, ora pela composição mineralógica, ora pelo hidrotermalismo interpretado pela análise do mapa Fator F, em que se percebe a existência de anomalias altas a muito altas nas porções onde estão assentados os quartzitos e xistos do Supergrupo Rio das Velhas.

O Homoclinal de Camargos pode ser verificado pela individualização das radiofáceis que leva a percepção da inversão das camadas litológicas. Em adição, a análise da razão ${ }^{238} \mathrm{U} /{ }^{232} \mathrm{Th}$ permite interpretar a idade relativa entre as litologias, o que fortalece a percepção desta inversão.

Pela integração da análise estrutural dos lineamentos geofísicos, inclusive das estruturas com indícios cinemáticos sugerindo as duas famílias de falhas direcionais que indicam zonas de cisalhamento (inclusive estão relacionadas à milonitização de litologias da região), a interpretação do mapa Fator $\mathrm{F}$ indicando as porções onde houve hidrotermalismo, e as evidências de campo que são os exemplares de ocorrências auríferas prospectadas, é plausível a implicação de que o ouro encontrado em Camargos ocorre das seguintes formas: o ouro primário ocorre em veios quartzosos e sulfetados que cortam os quartzitos do Grupo Maquiné e os xistos do Grupo Nova Lima e sua origem parece estar associada ao hidrotermalismo nas zonas de cisalhamento e aos sistemas de falhas de empurrão da Água Quente e de FundãoCambotas na região. O ouro secundário ocorre em canga ferrífera, nos córregos das serras quartzíticas como, por exemplo, junto a material 
cascalhoso concentrado em karrens, e nos depósitos aluvionares em planície de inundação confinada onde se instalou o vilarejo.

Em adição aos estudos geoeconômicos, tocante à forma de ocorrência de ouro na região de Camargos como detritos constituindo os quartzitos conglomeráticos do Grupo Maquiné, são sugeridos métodos de cunho local que consigam distinguir o corpo de quartzito das outras litologias. Eletrorresistividade e Ground Penetration Radar integrados podem gerar bons resultados na análise dos contatos litológicos neste caso, conduzindo aos cálculos de extensão e potência do corpo de minério, dentre outros aspectos.

Por fim, este estudo apresentou boa contribuição, visto que Camargos que é um marco histórico à mineração de ouro no Brasil, carece de estudos geológicos, especificamente geoeconômicos, sendo esta a oportunidade de trazer à luz do conhecimento implicações geológicas por intermédio de geofísica aplicada, que tem oferecido à geologia caminhos mais rápidos, eficientes e menos onerosos.

\section{AGRADECIMENTOS}

À Universidade Federal de Ouro Preto (UFOP), à Seequent, à CAPES, ao CNPq e à FAPEMIG pelo apoio. À CPRM e à CODEMIG pelo fornecimento gratuito do banco de dados aerolevantados. Ao pai do primeiro autor, Sr. Francisco Cardoso, cidadão nato da região de Camargos, pelo suporte aos trabalhos de campo e por transmitir inspiração tocante ao gosto exacerbado pela natureza.

\section{REFERÊNCIAS}

ALKMIM, F.F. \& MARSHAK, S. Transamazonian orogeny in the Southern São Francisco craton region, Minas Gerais, Brazil: evidence for paleoproterozoic collision and collapse in the Quadrilátero Ferrífero. Precambrian Research, v. 90, n. 1-2, p. 29-58, 1998.

ALMEIDA, F.F.M. O Cráton do São Francisco. Revista Brasileira de Geociências, v. 7, n. 4, p. 349-364, 1977.

ALMEIDA, F.F.M. \& HASUI, Y. (Coords). O Pré-Cambriano do Brasil. São Paulo: Edgard Blucher Ltda., 378 p., 1984.

BLUM, M.L.B.; SILVA, A.M.; JOST, H.; MENESES, P.R.; FUCK, R.A.; BROD, J.A.; TEIXEIRA, A.A.; SILVA, A.A.C.; SPIGOLON, A.L.D.; MAAS, M.V.R.; SOUZA, M.M.; MACEDO JÚNIOR, P.; LIMA, B.E.M.; CAMPOS, M.O. Aplicação de dados aerogeofísicos no mapeamento geológico do limite entre os terrenos arqueanos e proterozoicos da região de Crixás-Cedrolina, Goiás. Revista Brasileira de Geociências, v. 31, n. 3, p. 279-286, 2001.

BÖGLI, A. Karsthydrographie und Physische Speläologie. Berlin: Springer Verlag, 284 p., 1978.

CALÓGERAS, J.A.P. (Coord.). As minas do Brasil e sua legislação: Geologia econômica do Brasil. São Paulo: Companhia Editora Nacional, 507 p., 1938.

CARDOSO, L.H. Investigação geofísica na prospeç̧ão de cavidades naturais em litotipos ferríferos na região de Mariana, sudeste do Quadrilátero Ferrífero, Brasil. Ouro Preto, 2016. 102 p. Dissertação (Mestrado em Engenharia Mineral) - Departamento de Engenharia de Minas, Universidade Federal de Ouro Preto.

CARNEIRO, M.A. \& BARBOSA, M.S.C. Implicações geológicas e tectônicas da interpretação magnetométrica da região de Oliveira, Minas Gerais. Revista Brasileira de Geofísica, v. 26, n. 1, p. 87-98, 2008.

CARNEIRO, M.A.; TEIXEIRA, W.; CARVALHO JÚNIOR, I.M.; FERNANDES R.A. Ensialic tectonic setting of the Archean Rio das Velhas Greenstone Belt: Nd and Pb isotopic evidence from the Bonfim Metamorphic Complex, Quadrilátero Ferrífero, Brazil. Revista Brasileira de Geociências, v. 28, n. 2, p. 189-200, 1998.

CARVALHO, L.M.M. Integração de dados de geofísica aérea aplicada à geologia e à prospecção mineral no Distrito Esmeraldífero de Itabira-Ferros, Quadrilátero Ferrífero, MG. Brasília, 2006. 178 p. Tese (Doutorado em Geociências) Instituto de Geociências, Universidade de Brasília.

DERBY, O.A. The Serra do Espinhaço, Brazil. Journal of
Geology, v. 14, n. 5, p. 314-401, 1906.

DIAS, A.R. S. \& KANEKO, K.M. Aspectos litoestratigráficos e estruturais da região de Camargos, borda leste do Quadrilátero Ferrífero, Mariana, Minas Gerais, Brasil. Ouro Preto: Departamento de Geologia, Universidade Federal de Ouro Preto, 97 p., 1993.

DORR, J.V.N. Supergene iron ores of Minas Gerais, Brazil. Economic Geology, v. 59, n. 7, p. 1203 - 1240. 1964.

DORR, J.V.N. Physiographic, stratigraphic and structural development of the Quadrilátero Ferrífero, Minas Gerais, Brazil. Washington: Geological Survey Professional Paper, 110 p., 1969.

DORR, J.V.N.; GAIR, J.E.; POMERENE, J.B.; RYNEARSON, G.A. Revisão da estratigrafia pré-cambriana do Quadrilátero Ferrífero, Brasil. Belo Horizonte: Departamento Nacional da Produção Mineral, Divisão de Fomento da Produção Mineral, 31 p., 1957.

ENDO, I. \& FONSECA, M.A. Sistema de cisalhamento FundãoCambotas no Quadrilátero Ferrífero, MG: geometria e cinemática. Revista Escola de Minas, v. 45, n. 1, p. 15-17, 1992.

ENDO, I. Análise estrutural qualitativa do minério de ferro e encaixantes da minade Timbopeba - Borda Leste do Quadrilátero Ferrífero, Mariana, MG. Ouro Preto, 1988. 130 p. Dissertação (Mestrado em Geociências) - Departamento de Geologia, Universidade Federal de Ouro Preto.

ENDO, I. Regimes tectônicos do arqueano e proterozóico no interior da placa sanfranciscana: Quadrilátero Ferrífero e áreas adjacentes, Minas Gerais. São Paulo, 1997. 243 p. Tese (Doutorado em Geociências) - Instituto de Geociências, Universidade de São Paulo.

FAIRHEAD, JD \& MAUS, S. CHAMP satellite and terrestrial magnetic data help define the tectonic model for South America and resolve the lingering problem of the pre-break-up fit of the South Atlantic Ocean. The Leading Edge, v. 22, p. 779-783, 2003.

FERRAND, P. L'or a Minas Geraes. Belo Horizonte: Imprensa Official do Estado de Minas Geraes, p. 172 p., 1894.

FERREIRA, F.J.F.; CANDIDO, A.G.; ROSTIROLLA, S.P. Correlação gamaespectrométrica de afloramentos e poços: estudo de caso na Formação Ponta Grossa (Bacia do Paraná, Brasil). São Paulo. Revista Brasileira Geofísica, v. 28, n. 3, p. 371-396. 2010.

FILHO, F.A.F. \& FONSECA, M.A. Partição da deformação em 
regimes contracionais com obstáculos no antepaís: exemplo do Sistema de Falhas Água Quente, borda leste do Quadrilátero Ferrífero, MG. Revista Brasileira de Geociências, v. 31, n. 3, p. 267-278, 2001.

FREYBERG, B. (Coord.). Die Bodenschatze des Staates Minas Geraes. Stuttgart: Schwieizer, 453 p., 1934.

GOOGLE MAPS. 2018. https://www.google.com.br/maps/place/ Camargos,+Mariana+-+MG,+35420-000/@-20.2712875,43.4195187,14z/data=!3m1!4b1!4m5!3m4!1s0xa46e77dfc475 77:0xc852b47e2144910c!8m2!3d-20.2712887!4d-43.402009. Acessado em: 10ago2018.

HEINECK, C.A. \& SILVA, J.N.D. Programa de levantamentos geológicos básicos do Brasil, Cap Metalogenia 161-168 pp Folha Mariana SF 23-X-B-I, escala 1:100.000. CPRM/DNPM, 1993.

HOFF, R.; ROLIM, S.B.A.; BASTOS NETO, A.C. Mapeamento aerogamaespectrométrico da alteração hidrotermal associada à mineralização no Distrito Fluorítico de Santa Catarina, Brasil. Revista Brasileira de Geofísica, v. 22, n. 1, p. 45-56, 2004.

KEAREY, P.; BROOKS, M.; HILL, I. (Coords). An Introduction to Geophysical Exploration. Blackwell Science Publishing, 262 p., 2002.

LASA ENGENHARIA E PROSPECÇÕES S.A. Relatório final do levantamento $\mathrm{e}$ processamento dos dados magnetométricos e gamaespectrométricos. Levantamento Aerogeofísico de Minas Gerais, Area2 - Projeto Pitangui São João del Rei - Ipatinga. Belo Horizonte: Secretaria de Estado de Minas e Energia - SEME - Governo de Minas Gerais, 81 p., 2001.

MACHADO, N.; SCHRANK, A.; NOCE, C.M.; GAUTHIER, G. Ages of detrital zircon from Archean-Paleoproterozoic sequences: implications for Greenstone Belt setting and evolution of a Transamazonian foreland basin in Quadrilátero Ferrífero, southeastern Brazil. Earth and Planetary Science Letters, v. 141, n. 1, p. 259-276, 1996.

MARSHAK, S.; ALKMIM, F.F.; EVANGELISTA, H.J. Proterozoic crustal extension and the generation of dome and keel structure in an granite-greenstone terrane. Nature, v. 357, p. 491-493, 1992.

MAXWELL, C.H. The Batatal Formation. Boletim da Sociedade Brasileira de Geociências, v. 7. p. 60-61, 1958.

MAXWELL, C.H. Geology and ore deposits of the Alegria District, Brazil. Washington: DNPM/USGS, Professional Paper, 72 p., 1972.

MILSON, J. (Coord.). Field Geophysics - The Geological Field Guide Series. London: Wiley, 249 p., 2003.

MORAES, L.J. \& BARBOSA, O. Ouro no centro de Minas Gerais. Belo Horizonte: Boletim do DNPM/DFPM, 188 p., 1939.

NALINI-JR, H.A. Análise estrutural descritiva e cinemática do Flanco Sul e terminação periclinal do Anticlinal de Mariana e adjacências, região sudeste do Quadrilátero Ferrífero, Minas Gerais, Brasil. Belo Horizonte, 1993. 132 p. Dissertação (Mestrado em Geociências) - Instituto de Geociências, Universidade Federal de Minas Gerais.
QUEIROZ, L.C. Estudos comparativos de áreas com anomalias geofísicas na região da fazenda Mirabela, sul da Bahia. Salvador: Instituto de Geociências, Universidade Federal da Bahia, 54 p., 2012.

REIS, L.A.; MARTINS-NETO, M.A.; GOMES, N.S.; ENDO, I.; JORDT-EVANGELISTA, H. A bacia de antepaís paleoproterozoica Sabará, Quadrilátero Ferrífero, Minas Gerais. Revista Brasileira de Geociências, v. 32, n. 1, p. 2742, 2002.

ROESER, H.M.P. \& ROESER, P.A. O Quadrilátero Ferrífero MG, Brasil: Aspectos sobre sua história, seus recursos minerais e problemas ambientais relacionados. Geonomos, v. 18, n. 1, p. 33-37, 2010.

ROSSI, G. Quartzitos conglomeráticos auríferos da Sequência da Serra da Boa Vista, borda leste do Quadrilátero Ferrífero, MG, Brasil. São Paulo, 2010. 283 p. Dissertação (Mestrado em Geociências) - Instituto de Geociências, Universidade de São Paulo.

SILVA, E.R. DA. O Bandeirante João Lopes de Camargo. Revista ASBRAP, v. 20, p. 313-456. 2012.

SWAIN, C.J. Reduction-to-the-pole of regional magnetic data with variable direction, and its stabilization at low inclinations. Exploration Geophysics, v. 31, n. 1, p. 78-83, 1976.

TEIXEIRA, A.A.; SILVA, A.M.; PIRES, A.C.B.; MORAES, R.A.V.; SOUZA FILHO, C.R. Integração e análise de dados aerogeofísicos por meio da aplicação de técnicas de processamento digital de imagens e classificação não supervisionada: O exemplo do Greenstone Belt Rio das Velhas, Quadrilátero Ferrífero, MG. Revista Brasileira de Geofísica, v. 24, n. 4, p. 559-572, 2006.

TELFORD, W.M.; GELDART, L.P.; SHERIFF, R.E. (Coords). Applied Geophysics. New York: Cambridge University Press, 774 p., 1990.

UHLEIN, A. \& NOCE, C.M. Quadrilátero Ferrífero. In: HASUI Y.; CARNEIRO C.D.R; ALMEIDA F.F. DE; BARTORELLI A. (Coords). Geologia do Brasil. São Paulo: Beca, p. 228-235, 2012.

WALLACE, R.M. Moeda Formation. Boletim da Sociedade Brasileira de Geociências, v. 7, p. 59-6. 1958.

YONG TECHNOLOGY INC., software GeoRose, 2014.

Submetido em 3 de maio de 2019 Aceito para publicação em 11 de agosto de 2020 